\title{
National Phytosociological Database of Namibia
}

\author{
Ben Strohbach \& Fransiska Kangombe
}

\begin{abstract}
The National Phytosociological Database of Namibia (GIVD ID AF-NA-001) is a collection of true relevé data, excluding typical rangeland surveys or forestry inventories concentrating on either the graminoid and/or phanerophyte strata. At present consisting of 10,683 relevés collected by various researchers since 1956, the database is continuously being expanded with more relevés being sampled each year. Relevés have been collected for various purposes, including vegetation description and mapping, conservation planning, land use planning and environmental impact assessments. An important criterion for inclusion in this database is the collection of data according to the guidelines used for the Vegetation Survey of Namibia project. Ecoregions covered include the hyper-arid Namib, the arid Nama-Karoo, the Kalahari basin (including the southernmost Miombo transitional woodlands), as well as the central and north-western Namibian highlands.
\end{abstract}

Keywords: Angolan Mopane woodland; Kalahari; Nama-Karoo; Namib Desert; savanna; Succulent Karoo; Zambezian Baikiaea woodland.

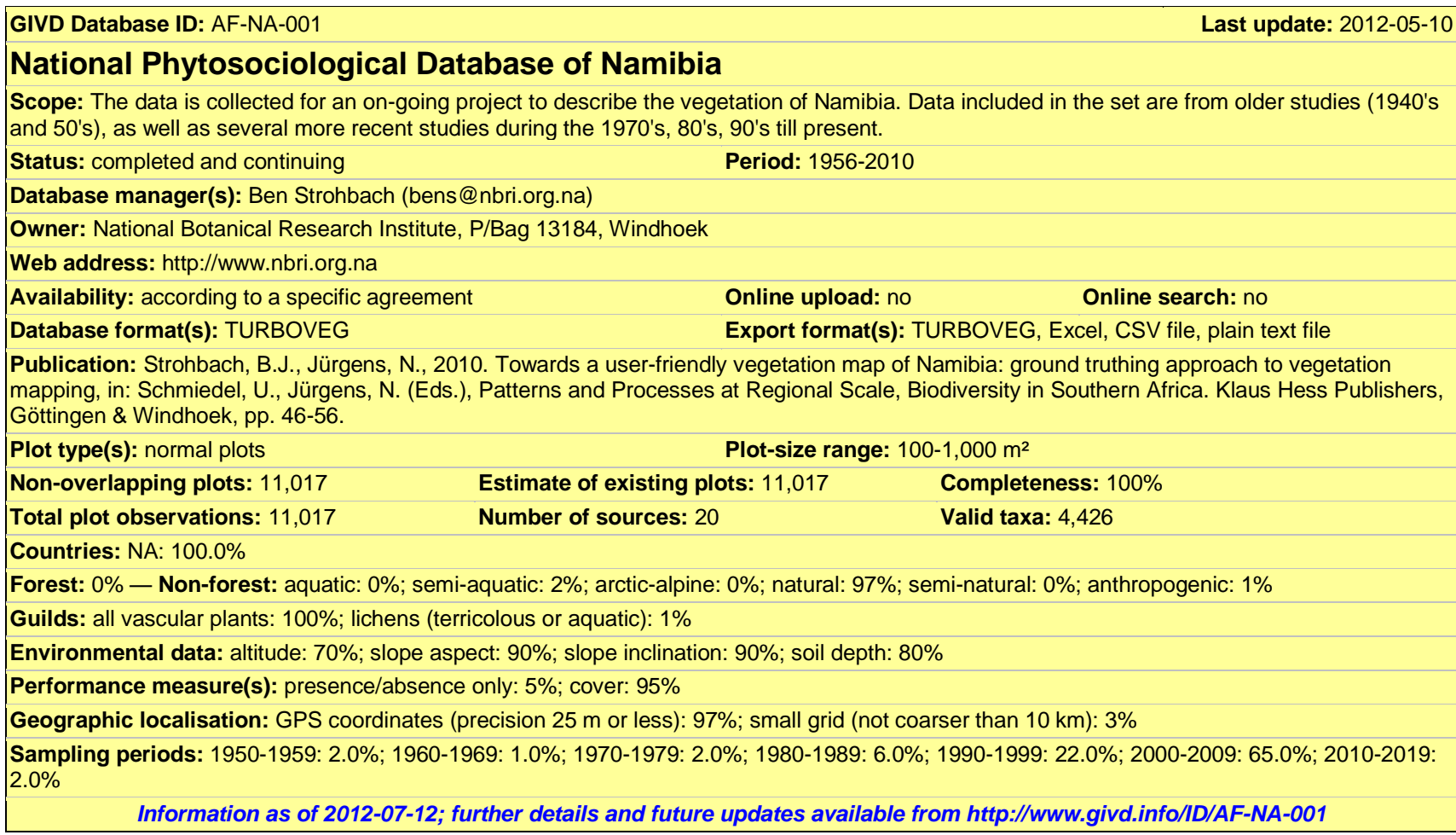

Ben Strohbach* (bens@ nbri.org.na), Fransiska Kangombe (fransiska@nbri.org.na)

National Botanical Research Institute, 8 Orban street, Windhoek, NAMIBIA

*Corresponding author 